www.jmscr.igmpublication.org

Impact Factor 5.244

Index Copernicus Value: 83.27

ISSN (e)-2347-176x ISSN (p) 2455-0450

crossref DOI:_https://dx.doi.org/10.18535/jmscr/v4i10.114

Journal Of Medical Science And Clinical Research

\title{
Total Thyroidectomy in a Recurrent Giant Goiter by Isthmus First Technique- A Case Report
}

\author{
Authors \\ Jitendra T. Sankpal ${ }^{1}$, Mukund B.Tayade ${ }^{2}$, Yogesh S. Torkadi ${ }^{3}$, \\ Shubham D.Gupta ${ }^{4}$, Jasmine R. Agarwal ${ }^{5}$, Ruchira R. Bhattacharya ${ }^{6}$ \\ ${ }^{1}$ M.S. General Surgery, Associate Professor and Unit Head, Dept. of General Surgery, \\ Grant Government Medical College and J. J. Group of Hospital, Mumbai, Maharashtra \\ Email:drjts_palmbeach@yahoo.co.in
}

\begin{abstract}
A recurrent giant multinodular goiter poses surgical challenges, especially when both lobes extend into retropharyngeal space. So, here we are reporting a technique of operating in such a scenario. The patient presented with a giant goiter extending to lateral part of neck and behind both ears, compressing the trachea and causing stridor with hoarseness of voice and puffiness of face and displacement of carotid to posterior triangle. Fibreoptic bronchoscopylguided intubation was done due to severe tracheal compression. Total thyroidectomy ${ }^{2}$ was performed by dividing the isthmus intraoperatively, sparing the parathyroids and Recurrent laryngeal nerves (RLN) at our center, which is a tertiary care teaching hospital. Once thyroid was removed, the outside diameter of trachea was assessed to be normal without any signs of tracheomalacia. Patient tolerated the procedure well and had no postoperative complications. There were no symptoms of RLN injury or any symptoms suggestive of hypoparathyroidism. Her breathing as well as voice improved significantly postoperatively. We conclude that total thyroidectomy with the technique of early division of isthmus in a case of giant thyroid swelling is associated with easier access to and dissection of deeper structures with better postoperative results and lesser complications.
\end{abstract}

\section{INTRODUCTION}

Total thyroidectomy has been used to treat patients with malignant thyroid disease. But for patients with benign thyroid disease, the safety and efficacy of total thyroidectomy is a matter of debate. Subtotal thyroidectomy ${ }^{3}$, that was previously the treatment of choice for benign thyroid disease, has been associated with high recurrence rates. The risk of permanent complications is greatly increased in patients who undergo surgery for recurrence of benign thyroid disease. So, total thyroidectomy is an operation that can be safely performed, with low incidence of permanent complications. This allows one to broaden its indications in various benign thyroid diseases, thus avoiding future recurrences and reoperations. Hence, it is the procedure of choice in such scenarios.

The case reported here is of a recurrent giant multinodular goiter, as shown in the picture, causing compressive symptoms. As the carotids were not involved, patient was planned for removal of thyroid gland. The patient withstood the procedure well in spite of the high-risk nature of the operation in her case. The patient was suspected to have intra-operative adhesions 
because of previous surgery, which may have lead to difficult dissection and intractable bleeding. The other risks that the patient faced were respiratory distress due to possible tracheomalacia $^{4}$, cardiovascular complications due to old age and postoperative hemorrhage.

\section{CASE DESCRIPTION}

A 58 years old female patient with a multinodular thyroid swelling since 25 years, measuring around $26 \times 16 \times 15 \mathrm{~cm}$, had a history of previous thyroid surgery 20 years back, when thyroid nodules were just scraped off the gland due to intraoperative adhesions and bleeding. Histopathologists reported the lesions as multinodular goiter. She was now planned for total thyroidectomy after thorough evaluation and pre-anesthetic check-up. On contrast enhanced computerized tomography (CECT) study of neck, a diffusely enlarged thyroid gland was revealed with presence of two large lobulated heterogeneously enhancing lesions, measuring $11.9 \times 7 \times 7 \mathrm{~cm}$ on right and $11.4 \times 8 \times 7.6 \mathrm{~cm}$ on left, involving the ishthmus of thyroid gland, measuring $35 \mathrm{~mm}$ superoinferiorly, causing moderate airway narrowing (tracheal diameter- $2.5 \mathrm{~mm})^{5}$, suggestive of multinodular goiter. Doppler study of neck was suggestive of both Carotids and Internal Jugular veins displaced laterally by a huge thyroid mass, however it does not appear to be involving thosevessels.PET scan was done for the patient and did not reveal any signs of malignancy or spread anywhere in the body. CT angiography of the neck was done, which showed multiple enlarged collateral vessels involving the pharyngeal wall with no mural involvement of major neck vessels. The patient's thyroid profile was done preoperatively and was found to be within normal limits. Fine needle aspiration cytology was done and was suggestive of colloid goitre. Indirect laryngoscopy showed mobile vocal cords with adequate chink. After awake fibreoptic bronchoscopy guided intubation, patient was put under general anaesthesia. A transverse skin crease incision was taken and good exposure ensured. After dividing the thinned out platysma and strap muscles, thyroid gland was visualized. Due to difficulty in mobilizing thyroid from lateral approach, decision to divide isthmus and then dissecting the thyroid medially to laterally was taken, which helped in better dissection and identification of both RLNs and parathyroid glands. Both the RLNs ${ }^{6}$ were spared and 2 parathyroid glands ${ }^{7}$ on the left superior pole were seen and saved. Complete excision of the enlarged gland was achieved with this approach. The trachea looked patent after removing the gland and hence, prophylactic tracheostomy was not done. The specimen obtained was around $23 \times 15 \times 15 \mathrm{~cm}$ in size and weighed about $2 \mathrm{~kg}$. Histopathology report revealed adenomatoid colloid goiter. The patient was shifted to ICU on ventilator support and was electively extubated on postoperative day 2 . Serum calcium measurement was done after 24 hours and was found within normal limits ${ }^{789}$. Patient had a weak voice after extubation, which became progressively stronger. She was started on thyroxine supplementation prophylactically in postoperative period. Patient did not have any major complication after the surgery; suction drain was removed by day 5; sutures were removed by day 7 and patient was discharged with stable vitals on day 8 .

Figure 1- Preoperative photograph of the patient showing large multinodular thyroid swelling

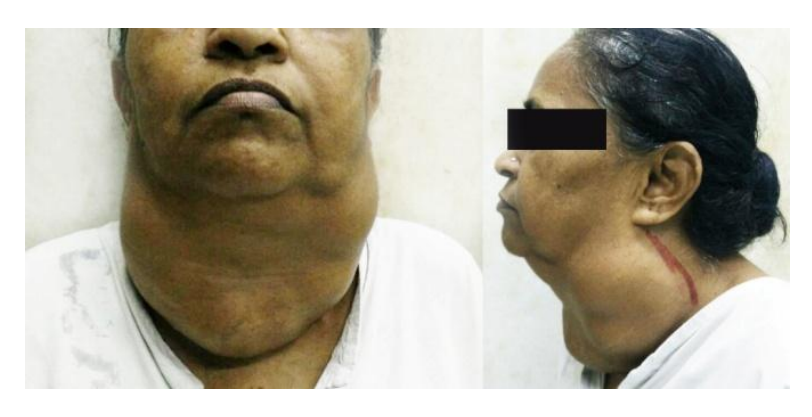




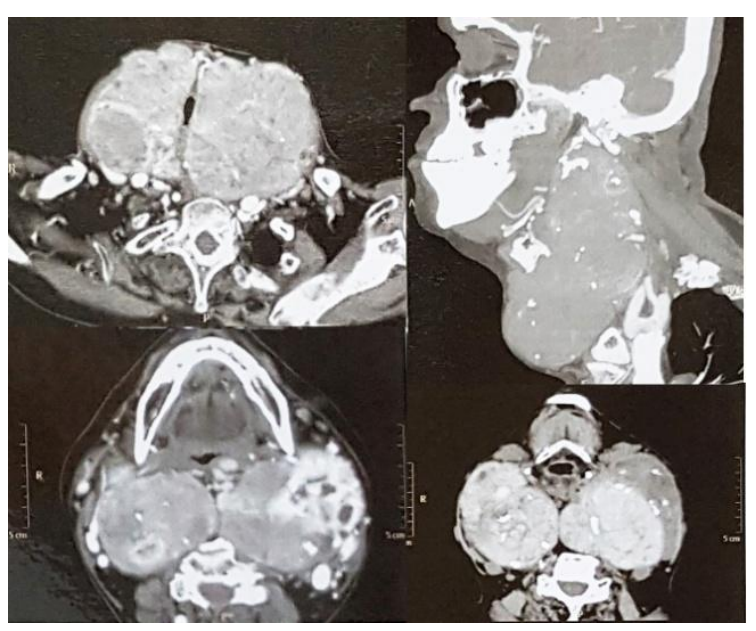

Figure 2- CECT neck showing large lobulated heterogeneously enhancing thyroid gland and its extent

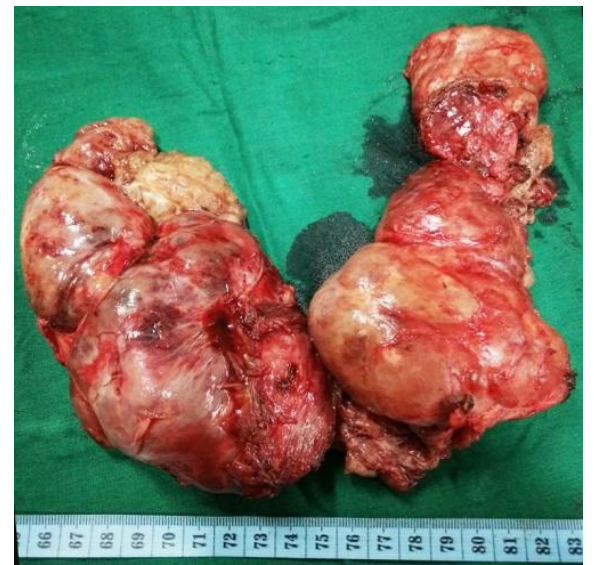

Figure 3- Thyroid specimen divided at isthmus

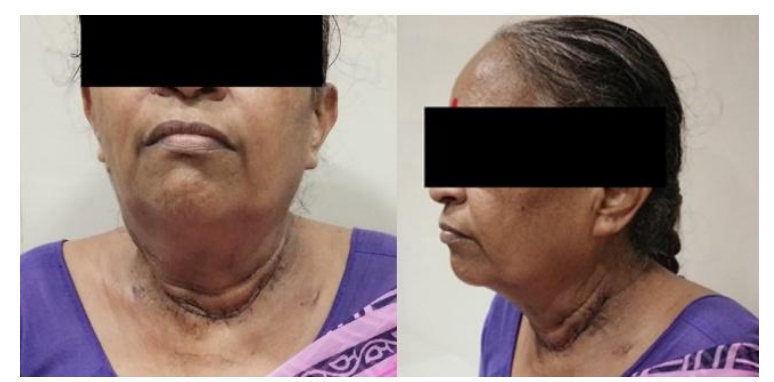

Figure 4- Postoperative photograph of the patient showing healthy suture line after discharge

\section{DISCUSSION}

This patient had recurrent giant multinodular goiter with compressive symptoms of stridor and hoarseness of voice. Urgent operative intervention was needed for the patient, so total thyroidectomy was done. Total thyroidectomy is the treatment of choice in such giant thyroid goiters. Division of isthmus at an early stage of surgery was found to give better dissecting planes with easy and early identification of RLNs and parathyroids which helped in preserving these vital structures, thereby, reducing the chances of postoperative hypocalcemia and hoarseness of voice.

\section{CONCLUSION}

Performing total thyroidectomy in cases with giant multinodulargoiter after dividing the isthmus ensures decreased chances of recurrence. It also aids in preservation of the RLNs and parathyroid glands, hence minimizing the complications.

\section{REFERENCES}

1. Collins SR, Blank RS. Fiberoptic intubation: an overview and update. Respir Care. 2014;59(6):865-78-80. doi:10.4187/respcare.03012.

2. Veyseller B, Aksoy F, Demirhan H, et al. [Total thyroidectomy in benign thyroid diseases]. Kulak burun boğaz Ihtis Derg $K B B=J$ ear, nose, throat. 19(6):299-303. http://www.ncbi.nlm.nih.gov/pubmed/200 30598. Accessed October 7, 2016.

3. Tezelman S, Borucu I, Senyurek Giles Y, Tunca F, Terzioglu $T$. The change in surgical practice from subtotal to near-total or total thyroidectomy in the treatment of patients with benign multinodular goiter. World J Surg. 2009;33(3):400-405. doi:10.1007/s00268-008-9808-1.

4. Srivastava D, Dhiraaj S. Airway management of a difficult airway due to prolonged enlarged goiter using locosedative technique. Saudi $J$ Anaesth. 2013;7(1):86-89. doi:10.4103/1658$354 X .109829$.

5. Mizuno J, Nakano $M$, Kasuya $M$, Nishiyama T, Hanaoka K. [A case of giant thyroid tumor with tracheal stenosis]. Masui. 2004;53(6):682-686. http://www.ncbi.nlm.nih.gov/pubmed/15242045.

Accessed October 7, 2016. 
6. Randolph GW, Kobler JB, Wilkins J. Recurrent laryngeal nerve identification and assessment during thyroid surgery: laryngeal palpation. World $J$ Surg. 2004;28(8):755-760. doi:10.1007/s00268004-7348-x.

7. Page C, Strunski V. Parathyroid risk in total thyroidectomy for bilateral, benign, multinodular goitre: report of 351 surgical cases. J Laryngol Otol. 2007;121(3):237241. doi:10.1017/S0022215106003501.

8. Pfleiderer AG, Ahmad N, Draper MR, Vrotsou K, Smith WK. The timing of calcium measurements in helping to predict temporary and permanent hypocalcaemia in patients having completion and total thyroidectomies. Ann $R$ Coll Surg Engl. 2009;91(2):140-146. doi:10.1308/003588409X359349.

9. Testini M, Gurrado A, Lissidini G, Nacchiero M. Hypoparathyroidism after total thyroidectomy. Minerva Chir. 2007;62(5):409-415. http://www.ncbi.nlm.nih.gov/pubmed/17947951. Accessed October 7, 2016. 